\title{
La historia como estado de excepción continuo: Sefarad, de Antonio Muñoz Molina
}

En su novela Sefarad (200I), Antonio Muñoz Molina hace partícipe al lector de los procesos de exclusión que experimentan aquellos individuos que, como consecuencia del Holocausto, la guerra civil española (1936-39) o el terror estalinista, son arrollados bajo los engranajes de la historia. Para ello, Muñoz Molina involucra al lector en un diálogo mutuamente informativo entre presente y pasado con el propósito de preservar la memoria, de hacerla relevante para un lector contemporáneo y de incluir a este último dentro de un contradiscurso que se concibe fuera del marco social y totalizador de la historia.

Palabras clave: Sefarad, Holocausto, exilio, estalinismo, guerra civil española

In his novel Sefarad (2001), Antonio Muñoz Molina inserts readers into the processes of exclusion experienced by those who, in the context of the Holocaust, the Spanish Civil War (1936-39), and Stalinism, are crushed by the machinery of history. Sefarad involves readers in a mutually informative dialogue between past and present in order to preserve memory, to make it relevant for a contemporary reader, and to engage the reader in a counterdiscourse that is conceived outside an all-encompassing historical framework.

Keywords: Sepharad, Holocaust, exile, Stalinism, Spanish Civil War

La experiencia nos ha enseñado que ningún proceso de la civilización es durable, que el exclusivismo e intolerancia la

minan por dentro, que pogromos y limpiezas étnicas se repiten. Formas de convivencia, bienser y espiritualidad de apariencia sólida pueden desplomarse de súbito. Así ocurrió en Sefarad para mayor gloria de sus Majestades Católicas. Juan Goytisolo, El sitio de los sitios 
En una serie de conferencias magistrales que llevó a cabo en 1976 , y publicadas en español bajo el título Genealogía del racismo, Michel Foucault demuestra que la historia es un instrumento de poder, lo que asume la posibilidad de un contradiscurso, es decir, de otra forma de contar la historia desde la perspectiva de aquellos individuos que experimentan el progreso propio desde la exclusión. En la novela Sefarad (200I), Antonio Muñoz Molina propone una aproximación ética a la historia, involucrando para ello al lector en un diálogo mutuamente informativo entre presente y pasado, y en el que se difuminan los límites entre la realidad y la ficción. Esta aproximación, junto con el tratamiento que hace la novela del Holocausto, del terror estalinista y del exilio español de la posguerra, responde a tres propósitos básicos: a la necesidad de preservar la memoria; de hacerla relevante para un lector contemporáneo; y de incluir a este último dentro de un contradiscurso que se concibe fuera del marco social y totalizador de la historia. Desde este enfoque, Sefarad subraya la existencia de un estado de excepción continuo que, siguiendo la tradición de los oprimidos a la que alude Walter Benjamin en su octava tesis sobre la filosofía de la historia (257), hace partícipe al lector de la excepcionalidad y el desarraigo que acompaña a todo proceso histórico desde la expulsión de los judíos que promulgan los Reyes Católicos en 1492 hasta nuestros días.

Sefarad construye un collage literario sobre las ruinas de la historia social y política europea y española, yuxtaponiendo para ello diecisiete narrativas independientes conectadas por la exclusión como tema recurrente y por la intervención de un narrador primario cuyas reflexiones hilvanan una amplia gama de historias y experiencias que, a primera vista, pueden parecer dispares. Tomando la expulsión de 1492 como punto de partida, Muñoz Molina encuadra estos relatos bajo el símbolo de "Sefarad", es decir, de una temporalidad y de un lugar marcados por la intolerancia y

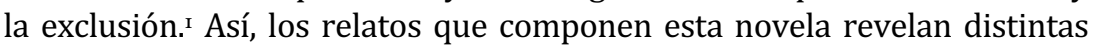
facetas de la excepcionalidad política y social - del infortunio, según lo califica Muñoz Molina en su artículo "Mis compatriotas" - que han agrupado "durante siglos a los judíos y herejes y a los desterrados de la intolerancia española". Como aclara el narrador principal de Sefarad:

[A]l fundar la Inquisición y expulsar a los judíos, los Reyes Católicos prolongaron una tradición milenaria de infamias y trazaron la lógica futura y homicida del antisemitismo europeo, pero también ofrecieron a los ilustrados y a los demócratas de los siglos futuros el paradigma exacto de su condición: un liberal de i8I2 o de I820, un republicano de 1939 se convertía inevitablemente en judío, en peregrino, en proscrito, o bien en cristiano nuevo que debía esconder muy hondo el secreto de sus convicciones. (Muñoz Molina, Sefarad 7ı9) 
Al tomar la exclusión como eje de su narrativa, Sefarad articula aquello que Foucault denomina como una contrahistoria, es decir, un discurso que, a diferencia de la historia académica, no trata de reconstruir ni ordenar una serie de eventos históricos, sino introducir lo discontinuo en nuestro propio ser (Genealogía 46). Para ello, la novela propone una aproximación empática a la historia desde la que desbarata toda percepción de estabilidad y seguridad sobre la que se asienta el presente, penetrando en aquello que Maurice Blanchot denomina como "lo real imposible", es decir, "that share of disaster wherein every reality, safe and sound, sinks" (38). De hecho, la novela no plantea un repaso de los marcos históricos, de los contextos políticos ni de las consecuencias que se pueden extraer de éstos, sino que se trata, como indica Gómez López-Quiñones, de "una narración mucho más preocupada por el 'qué' que por los 'cómo' y los 'por qué"' (63). De este modo, y renunciando a toda interpretación social y totalizadora de la historia, Sefarad articula un discurso transversal y polifónico en el que subraya, como indica Valdivia, que "el terror no conoce fronteras ni se esfuma cuando termina un conflicto. Al contrario, nuevas formulaciones del terror se asientan en territorios aparentemente alejados entre sí para arrojar a los individuos a una vida de desposesión y destierros permanentes" (Muñoz Molina, Sefarad IO2).

La normalización histórica del desarraigo y de la exclusión que plantea Sefarad es consistente con la interpretación del estado de excepción que proponen Foucault, Walter Benjamin, Giorgio Agamben y Jacques Derrida, entre otros. Estos autores afirman que, más allá de toda particularidad social o política, el estado de excepción constituye el eje de la historia e incluso de la normalidad democrática y capitalista desde la cual, presumiblemente, se aproxima el lector ideal a este texto. ${ }^{2}$ Derrida, por ejemplo, habla de cómo el estado de excepción se hace patente en la marginalidad como forma de violencia (legal, discursiva e incluso física) que opera dentro de la propia ley (Derrida, Fuerza 66). De modo similar, Agamben establece que "the normative aspect of law can be thus be obliterated and contradicted with impunity by a governmental violence that, while ignoring international law eternally nevertheless still claims to be applying the law" (State 87).3 El estado de excepción deja así de interpretarse como una anomalía política y social para integrarse, siguiendo a Hans-Georg Gadamer, "en un horizonte histórico que es coextensivo con la vida que vivimos y que hemos vivido" (42-43). Como consecuencia, Sefarad narra la historia, no como las cuentas de un rosario, según la metáfora que utiliza Benjamin en su décimoctava tesis sobre la filosofía de la historia (273), sino como un discurso cuyo sentido viene determinado, 
según afirma este último autor, por los destrozos que la estela del progreso, o de la historia, van acumulando a su pie (257).

Siguiendo esta lógica, y valiéndose de un narrador primario que conecta formalmente los distintos relatos, Sefarad explora el impacto que produce el diagnóstico médico en un enfermo terminal ("Valdemún"); la pérdida de identidad que experimentan los judíos durante el Holocausto ("Oh tú que lo sabías") y que producen también las purgas ideológicas del estalinismo ("Münzenberg" y "Quién espera"); el desarraigo de un campesino andaluz que sufre de desposesión y desempleo tras emigrar a Madrid ("Sacristán"); la del funcionario público que vive una vida familiar y profesional frustrada ("Olympia"); la de la monja con sueños de libertad que aspira a vivir en Estados Unidos durante la posguerra española ("América"); la de Amaya Ibárruri, hija de Dolores Ibárruri, La Pasionaria, quien tras pasar prácticamente toda su vida exiliada en Rusia, se encuentra fuera de lugar en Madrid ("Sherezade"); y así hasta completar dieciséis episodios que se extienden a lo largo y ancho de la historia europea contemporánea, y que incluso se aventuran en la historia de las últimas dictaduras militares de Argentina y Uruguay ("Dime tu nombre").4 Se trata, en definitiva, de una reconstrucción, necesariamente incompleta, de la inagotable historia de los hijos de Sefarad, es decir, de quienes, en nombre del progreso, son desplazados a los arcenes del desarrollo histórico, del orden jurídico y de la modernidad.5

A la hora de presentar estos relatos, Sefarad evoca la estructura formal de Las mil y una noches, texto al que alude el capítulo "Sherezade". Este título hace referencia, según indica Justo Serna, a la narradora de la obra medieval quien, de forma similar al narrador primario de Sefarad, cuenta, sin parar, "vidas" que son relatos de muerte o de milagros de supervivencia, desplazando a la muerte bajo la garantía de permanencia que, como indica Foucault, ofrece el lenguaje ("History" 54 ). Más aún, y siguiendo el modelo oral y dialéctico de la recopilación medieval, la novela responde a un doble propósito ético: el de preservar la memoria en un momento en que los últimos supervivientes del Holocausto, del estalinismo y de la guerra civil española han cumplido ya casi en su totalidad con su ciclo biológico; y el de hacer esta memoria relevante para un lector que, con el paso del tiempo, tiende a desligarse de los desastres que vivieron generaciones pasadas. ${ }^{6}$

En relación al primero de estos propósitos, la novela se plantea como remedio contra un olvido que se presume inmediato pues, como indica el narrador en el capítulo "Oh tú que lo sabías" - en referencia a un poema de Baudelaire - "hasta algunos de los mayores infiernos sobre la tierra quedan borrados al cabo de una o dos generaciones y llega un día en que no queda ni un solo testigo vivo que pueda recordar" (Muñoz Molina, Sefarad 3II). Ni 
siquiera los campos de exterminio permanecen como lugares de la memoria, ya que, conforme pasa el tiempo, acaban asimilados al espacio que los rodea, sepultando consigo miles de historias y experiencias que no quedan registradas en ningún sitio. Así, por ejemplo, en el último relato mencionado, Isaac Salama, un judío sefardí que sobrevive a la ocupación nazi de Polonia y que se refugia en el protectorado español de Marruecos, visita el campo de exterminio en el que décadas atrás asesinan a su madre y dos hermanas. El guía que lo acompaña subraya la fragilidad de todo lo que observa, lamentándose de que, una vez que él muera, nadie advertirá "la presencia de esos accidentes menores en el claro del bosque, ni repararía en que el crujido metálico bajo las suelas de sus botas era una cuchara que en algún momento fue uno de los tesoros más valiosos para la vida de un hombre" (315-16).

Con el propósito de preservar estas memorias, el relato traspone la experiencia individual a la memoria colectiva, garantizando la continuidad de la primera a través de la fusión entre estos dos planos. Para ello, el sujeto de pensamiento y de dicción deja de concebirse como un yo para interpretarse como un nosotros, como refleja el discurso del padre de Isaac Salama, cuyo nombre no se revela en ningún momento. Ajustándose una vez más al modelo de Las mil y una noches, y siguiendo también la tradición oral sefardí, el padre de Isaac Salama funde, por un lado, su historia personal con la colectiva y, por otro, el presente con el pasado, sin distinguir los límites entre estas temporalidades y planos narrativos. 7 Como indica Isaac Salama - a quien también se refiere el narrador como el señor Salama - su padre "hablaba siempre en primera persona del plural: habíamos emigrado al norte de África, y luego algunos de nosotros nos establecimos en Salónica, y otros en Estambul, adonde llevamos las primeras imprentas, y en el siglo XIX llegamos a Bulgaria, y a principios del XX uno de mis abuelos ... se asentó en Budapest" (Muñoz Molina, Sefarad 377-78). El padre del señor Salama sintetiza en una oración distintas voces y temporalidades, como si se tratara, según indica su hijo, de "una sola vida que hubiera durado casi quinientos años" (337). Sefarad deja así de entenderse únicamente como un espacio geográfico o como un referente histórico asociado a la expulsión de ${ }^{4} 492$ para transformarse en una forma de pensar y narrar la historia, lo que supone una contribución cualitativa, y no solamente cuantitativa, a la hora de construir un discurso transhistórico e intersubjetivo marcado por la no pertenencia.

Siguiendo este modelo narrativo, Sefarad elimina también la primacía de un relato sobre otro, manteniendo la singularidad de cada experiencia y evitando establecer relaciones de causa y efecto que son más propias de la labor intelectiva del historiador que de una realidad, por naturaleza, azarosa 
y desordenada. Como consecuencia, Sefarad no se adhiere a una hipótesis, ya que esto supondría una falsificación del pasado y, de acuerdo con Pérez Simón, un error ético y estético (259). Más aún, la novela rechaza toda metodología histórica, entendiendo por este concepto, y, en palabras de Tuñon de Lara, "los conjuntos de operaciones intelectuales de ordenación y de evaluación de la materia prima de la historia (fuentes), para aplicar unas técnicas que nos permitan conocer los objetos históricos que nos hemos propuesto" (3). Frente a este modelo historiográfico, el narrador primario de Sefarad interpreta la historia como una genealogía en la que todos los acontecimientos aparecen enmarañados, lo que explica la yuxtaposición de experiencias de distinta densidad ética y emotiva a lo largo de la novela.

Aun cuando se trate de un debate ampliamente transitado por la crítica, cabe señalar que, en el contexto de Sefarad, esta yuxtaposición no implica equivalencia, cuestión que ha motivado desacuerdos entre distintos autores a la hora de evaluar los propósitos y la estética de la novela. Martín Lareque, por ejemplo, afirma que el paralelismo entre "los perseguidos y exiliados del nazismo y el comunismo, por un lado, y el de los desarraigados que viven vidas frustradas o auténticas, por otro, puede llegar a resultar incómodo", impresión que comparte con María Jesús López Navarro. Según esta última autora, al obviar que cada trauma social es distinto, la novela plantea una concepción esencialista de la historia (López Navarro Ioo). Desde otro enfoque, Antonio Gómez López-Quiñones afirma que el propósito de esta superposición no es establecer criterios comparativos, sino erigir el Holocausto como una herramienta analítica más (Gómez 6r). Nicola Gilmour concluye que, "if this kind of literature, an expression of the imagination combined with testimony of real events, can summon up a feeling of connection with the alienation and suffering of the past, then perhaps this is an acceptable risk to take" (847).

En relación a este debate, y en una aproximación parcial a la postura de Gómez López-Quiñones, Sefarad establece un equilibrio entre la singularidad de cada experiencia y su carácter ejemplar, entendiendo por este último concepto la manifestación de un fenómeno o de una categoría más general que supera una lectura literal e intransferible de un acontecimiento histórico determinado (Todorov 3I). Mientras que el conjunto de la novela construye una memoria ejemplar - en la que se pueden establecer analogías entre distintos acontecimientos históricos cada capítulo aborda una experiencia singular que ni se disuelve ni se explica al compararse con las otras. Así, y como indica Tzvetan Todorov, "La memoria ejemplar generaliza, pero de manera limitada; no hace desaparecer la identidad de los hechos, solamente los relaciona entre sí, estableciendo comparaciones que permiten destacar las semejanzas y 
diferencias" (45). De hecho, la asociación entre las distintas experiencias que se narran en Sefarad depende, no de su continuidad, sino de la semejanza entre las mismas, lo que permite buscar una explicación a una serie de acontecimientos que, individualmente y siguiendo una lectura literal de cada capítulo, podrían parecer dispares.

En la construcción de esta memoria ejemplar, Sefarad confiere al lector la tarea de establecer analogías entre los distintos relatos y experiencias, privándole de una interpretación definitiva que dé un sentido unívoco a la historia e incluso a los distintos relatos que componen la novela, lo que transforma el propio proceso de lectura en una experiencia de desarraigo. Así, y siguiendo la estrategia de la fuga musical - una de las señas de identidad formal de esta novela - algunos de los personajes circulan por distintas narrativas y, por consiguiente, por espacios, temporalidades y momentos existenciales diferentes, lo que evoca el discurso oral del padre del señor Salama. ${ }^{8}$ Como consecuencia, el lector se ve obligado a establecer conexiones entre distintas partes del texto y entre personajes cuya identidad está en un proceso continuo de construcción.9

A modo de ejemplo, la intervención del lector es fundamental a la hora de construir el personaje de sor María de Cólgota, protagonista del relato "América". Ajena a toda vocación religiosa e hija de represaliados por el franquismo, sor María de Cólgota ingresa en un convento al acabar la guerra civil, no para garantizar su "felicidad en el otro mundo", sino para tener "algo de seguridad en éste", y no acabar "rapada y afrentada en público" como su madre (Muñoz Molina, Sefarad 577). Las aspiraciones de esta joven quedan así ahogadas tras los muros de un convento, lo que la lleva a plantearse la posibilidad de emigrar a Estados Unidos y vivir como las mujeres americanas, quienes, según ella, "beben refrescos y fuman, sin que nadie piense que son putas, y se pintan las uñas no solo de las manos, sino también las de los pies, y si tienen alguna queja del marido se divorcian de él" (58587). Conforme formula estos ideales, sor María de Cólgota desvela su identidad, primero como Francisca - su nombre legal - y, después, como Fanny, es decir, como una joven que, educada por su padre en los principios de la Segunda República, aspira "a hablar inglés, a jugar al tenis, a escribir a máquina y a conducir automóviles" (575).

Esta transformación de sor María de Cólgota en Francisca y posteriormente en Fanny se inicia cuando la monja accede a las solicitudes sexuales de un zapatero mujeriego de nombre Mateo Chirino (conocido también como Mateo Zapatón), según revela el narrador en el capítulo "Sacristán". En el transcurso de estas relaciones, sor María de Cólgota pasa a ser un personaje híbrido, cuya imagen e identidad como religiosa contrastan con su comportamiento como una mujer liberal que tiene 
control y agencialidad sobre su cuerpo, lo que viola presumiblemente las expectativas iniciales del lector. Así, cuando pierde su virginidad con el zapatero durante un encuentro clandestino que tiene lugar en el propio convento - y mientras experimenta su primer orgasmo - la monja invoca un "Ave María... con un suspiro largo y plácido" (Muñoz Molina, Sefarad 573), a lo que el zapatero responde "no sin cierta inquietud por la irreverencia ... Sin pecado concebida" (573). A partir de este momento, la monja recurre al sexo para tratar de convencer al zapatero de que se exilie con ella en América. La protagonista, no obstante, no logra este último propósito, como sugiere la postal que envía posteriormente a su amante y en la que, detrás de una imagen de la Estatua de la Libertad, la bandera de Estados Unidos y el perfil de los rascacielos de Nueva York, le escribe: "Recuerdos de América" (595).

Este personaje femenino reaparece al final de la novela, en el relato "Sefarad", transformada en una trabajadora de la Hispanic Society de Nueva York, cuando ya está cerca de la edad de jubilación y en un español cuyos dejes anglosajones y caribeños delatan una vida transcurrida en el exilio. ${ }^{\circ}$ El reconocimiento de este personaje décadas después produce en el lector un efecto similar al de la anagnórisis, como si se tratase de una pieza suelta del puzle incompleto que presenta el capítulo "América". De hecho, el relato no establece una conexión explícita entre sor María de Cólgota y la empleada del museo - quien no se identifica por ninguno de sus nombres en el relato "Sefarad" - sino que es el lector quien debe reconocer a la antigua monja bajo la imagen de "una empleada o secretaria americana ... que vive sola y no se ocupa mucho de arreglarse, que se corta el pelo de cualquier modo y lleva jerseys oscuros y pantalones de hombre, zapatos entre ortopédicos y deportivos" (Muñoz Molina, Sefarad 730).

No obstante, la novela aporta algunas claves básicas que permiten al lector relacionar las dos iteraciones de este mismo personaje. La trabajadora del museo, por ejemplo, recuerda la fascinación que siente de joven por la libertad de las mujeres estadounidenses mientras disfruta de un cigarro: "Qué lujo, fumarme un pitillo tomándome un café negro después de comer ... cuando era muy joven, yo quería escaparme de España y venir a América porque aquí las mujeres podían fumar y llevar pantalones y conducir automóviles" (Muñoz Molina, Sefarad 735-36). Al margen de estas referencias, la novela elimina décadas de la vida del personaje que el lector debe reconstruir sobre la base de alusiones breves que hace la primera como, por ejemplo, la pasión que adquiere por la literatura española tras estudiar en la universidad neoyorquina de Columbia - pero que no revelan su verdadera identidad. De hecho, si nos limitamos a la información que aporta el relato "Sefarad", y como indica el narrador de este capítulo, "no 
llegamos a saber nada de su verdadera vida, ni siquiera su nombre" (739). "Sefarad" rellena así algunos vacíos de "América" y continúa desarrollando un personaje cuya construcción definitiva queda, en última instancia, a expensas del lector. Se trata en definitiva de una estrategia que, como afirma Valdivia, "está en perfecta consonancia con todo el espíritu narrativo de la novela que incluye a un lector activo, constructor explícito del sentido" (593).

En lo que puede interpretarse como un salto estético y formal arriesgado - y siguiendo la aproximación genealógica a la historia que plantea Sefarad - este último relato comparte una preocupación esencial que aproxima a su protagonista - una exiliada de la Guerra Civil - a las víctimas del Holocausto y del estalinismo: la tragedia que supone, como indica David Herzberger, la alienación forzada del individuo y que solo lleva al sufrimiento, al exilio y a la muerte (Herzberger 53 )." Independientemente del evento histórico en cuestión, la pertenencia o la exclusión - o, lo que es lo mismo, la supervivencia o la muerte en un sistema totalitario o dictatorial - están íntimamente ligadas a la identidad como factor que, al estar sujeto a vicisitudes contextuales, escapa al control del individuo. Como afirma el narrador en el capítulo "Doquiera que el hombre va", "Eres no tu conciencia ni tu memoria sino lo que ve un desconocido" (Muñoz Molina, Sefarad 506). El filósofo Hanns Mayer, por ejemplo - quien cambia su nombre a Jean Améry tras el Holocausto - vive su juventud como un protestante austriaco que, al margen de las tradiciones judías, es educado en el amor a su país, hasta el punto de que se alista como voluntario en la Primera Guerra Mundial. Sin embargo, tras leer la proclama de las leyes raciales de Nuremberg de 1935, Mayer era "lo que jamás había pensado: un judío, y además no era más que eso, toda su identidad se reducía a esa sola condición" (7OI).

De forma similar, el padre del señor Salama deja de identificarse con todos aquellos elementos que definen inicialmente su identidad como un ciudadano europeo y moderno, rechazando "la Europa que él había amado sobre todas las cosas y de la que se había enorgullecido, Brahms y Schubert y Rilke, y toda aquella gran basura de lujo que le tenía trastornada la cabeza y de la que luego renegó" (Muñoz Molina, Sefarad 336-37). Tras el Holocausto, y una vez afincado en Tánger, este personaje se refugia en las tradiciones judías ortodoxas que rechaza en su juventud y que pasan a constituir la esencia de su nueva identidad. De hecho, y según indica el señor Salama, el padre se convierte en "un judío celoso de la ley y aislado y huraño entre los gentiles, él que de niños jamás nos llevó a la sinagoga ni a mis hermanas ni a mí, ni celebró ninguna fiesta litúrgica” (337). 
En el contexto de la persecución nazi, la identificación de estos personajes como judíos - en detrimento de cualquier otra marca de identidad - supone también su reducción a una forma de vida nuda, es decir, a una existencia puramente biológica ante la que la ley pierde su significado pero no su fuerza. ${ }^{12}$ Los personajes pasan así a encarnar la condición del culpable perfecto, cuyo referente explícito en la novela de Muñoz Molina es Joseph K., protagonista de El proceso, de Frank Kafka, quien "sin saber el delito que ha cometido es sometido a un juicio fantasmal en el que de antemano es culpable y ejecutado luego como un perro en un descampado en mitad de la noche" (Muñoz Molina, Sefarad 388). Joseph K., y al igual que ocurre posteriormente con la mayoría de los personajes de Sefarad, arrastra su condición como culpable como una cualidad intrínseca, es decir, como un estado de excepción que interioriza y que nadie puede identificar a simple vista. Al remitirse a este referente, Sefarad alude también a la necesidad de establecer una comunidad entre estos personajes, rompiendo con el aislamiento al que los somete el devenir de la historia. De hecho, y aun cuando no llegue a desarrollarlo, Kafka delinea los principios de esta comunidad que plantea Sefarad, como sugiere la cita de El proceso con la que, a modo de epígrafe - y según indica Herzberger (89) - inicia Muñoz Molina su novela: 'SSí,' dijo el ujier, 'son acusados, todos los que ve aquí son acusados.' ‘De veras?,' dijo K. 'Entonces son compañeros míos'” (Kafka, citado en Sefarad 157).

Al igual que ocurre con Joseph K., la desposesión que experimentan los personajes de Sefarad no viene determinada por una causa concreta, sino por variables históricas que, tras un giro inesperado, los conduce al destierro e incluso al exterminio. En el relato "Quien espera", por ejemplo, y por motivos no aclarados, la historiadora Eugenia Ginzburg pierde su trabajo en la universidad tártara de Kazán, es expulsada del Partido Comunista y recluida en un campo de trabajo en Siberia. De modo similar, el dirigente comunista alemán Willi Münzenberg - quien convierte al dirigente soviético Georgi Dimitrov en un héroe de la resistencia popular contra los nazis en Alemania - pasa a ser ignorado por su antiguo camarada, quien ni siquiera atiende a sus llamadas una vez que el primero es tachado de sospechoso por el estalinismo. Como consecuencia, Münzenberg - quien en un momento de su vida "lo fue todo" (Muñoz Molina, Sefarad 394) en el comunismo europeo - acaba colgado de un árbol en circunstancias nunca aclaradas.

Esta aproximación al desarraigo y a la exclusión como experiencias que se derivan de los vaivenes de la historia e incluso del azar sirve también como estrategia a la hora de involucrar al lector en las experiencias de los personajes. En virtud de este propósito, Sefarad actúa a contracorriente de 
un discurso histórico que surge, como indica Michel de Certeau, "only when a present is divided from a past", y que se fundamenta sobre "an initial act of exclusion [that] separates current time from past time, or the living from the dead" (Certeau viii). Más aún, y siguiendo el modelo de memoria prostética que propone Alison Landsberg, la novela actúa como un lugar de memoria, es decir, como un espacio donde, de forma similar al museo o al teatro, se representan y también se construyen memorias colectivas que no se fundamentan sobre la experiencia directa del lector o espectador, y en el que la diferencia entre pasado y presente pierde todo sentido. ${ }^{13}$ En este lugar de memoria, el narrador se sitúa en un plano sincrónico con respecto al lector desde el cual lo invita a reflexionar sobre experiencias que fluyen entre la realidad y la ficción, y que tienen lugar en distintos espacios y temporalidades. A pesar de sus particularidades, se trata de experiencias que, unidas por el nexo de la exclusión, hermanan a personajes tan dispares como Münzenberg, Ginzburg, al señor Salama y, en última instancia, al propio lector: "Qué harías tú si supieras que de un día para otro pueden expulsarte, que bastarán una firma y un sello de lacre al pie de un decreto para que tu vida entera quede desbaratada ... y te veas arrojado a los caminos, expuesto a la vergüenza, obligado a despojarte de todo lo que creías tuyo" (Muñoz Molina, Sefarad 696).

A través de esta apelación directa - formulada en esta ocasión en tiempo condicional y en subjuntivo - el narrador de Sefarad establece una relación dialógica entre pasado y presente, neutralizando la barrera psicológica que protege al lector de un pasado incómodo y que podría llevarle a asumir que los horrores del estalinismo, de la guerra civil, del exterminio nazi e incluso de la expulsión de 1492 solo pueden pasarles a otras personas, en otros lugares y en otras coyunturas históricas. Para desarticular esta falacia, Muñoz Molina resta toda excepcionalidad a los eventos y circunstancias históricas que aborda en Sefarad. De hecho, la novela no se adentra en los campos de exterminio nazis ni en la Gulag soviética - lo que establecería de antemano la excepcionalidad de estos relatos - sino que, como sugiere la fotografía que aparece como portada en la edición de Cátedra de Sefarad, se queda - y deja al lector - en las puertas de Auschwitz. En otras palabras, la novela no exalta el carácter trágico del destierro y del exterminio, sino que sumerge a los personajes en un proceso de espera e incertidumbre que resulta desquiciante, pero en el que, a simple vista - y al igual que ocurre con Joseph K. en la novela de Kafka - no pasa nada. De hecho, resulta llamativo que, en una extensa novela sobre el Holocausto, el terror estalinista, la guerra civil española y su posguerra, tan solo se aluda de pasada a la muerte de contados personajes, como pueden ser Münzenberg, y la madre y hermana de Isaac Salama. No obstante, el 
propósito de Sefarad no es impactar al lector con escenas de desolación, sino enfatizar la normalidad con la que todo transcurre. De este modo, la novela desarticula la alteridad de la situación histórica y social que viven los personajes, de forma que el lector pueda identificarse con estos últimos sin necesidad de recurrir a la suspensión de la credibilidad.

El día a día de Ginzburg, por ejemplo, apenas se altera una vez que ha sido tachada de sospechosa por el Partido Comunista, aun cuando ello implique que puede ser arrestada o incluso asesinada en cualquier momento por sus propios camaradas. Como indica el narrador, "nadie había venido a buscarla, no le apuntaban con una pistola, no la habían esposado ni encerrado en una furgoneta negra, podía salir como cualquier mañana y caminar hacia la estación, podía confundirse con la multitud que asaltaba los andenes en cuanto se acercaba un tren ..." (Muñoz Molina, Sefarad 26o). De hecho, y tras abrigar a su hijo y llevarlo al colegio como cada día, Ginzburg acude por su propio pie a la central del partido junto a su marido, quien se despide de ella sin saber cuándo o si volverán a verse. Al enfatizar el estado de negación de Ginzburg, Sefarad confronta al lector con la necesidad de cuestionar su propia seguridad ontológica, lo que transforma el texto en un contraespejo de la aparente normalidad que separa al primero de las experiencias de los personajes y desde la que da por superados los destrozos (según la expresión de Benjamin) que la historia va dejando por su camino (252). Como indica Slavoj Žižek en relación a la Guerra de Bosnia (1992-95) - y en una afirmación que es relevante a la hora de reflexionar sobre el Holocausto y el estalinismo - en el momento en que el horror se revela en toda su normalidad, "the frontier that separates 'us' from 'them' is exposed in all its arbitrariness, and we are forced to renounce the safe distance of external observers" (2).

Con objeto de restar toda excepcionalidad a la historia, la novela identifica también las experiencias sociales y políticas de los personajes con la situación de un enfermo que ya se ve "al otro lado de la línea invisible, la línea definitiva que separa a los sanos de los enfermos" (Muñoz Molina, Sefarad 443). Las fronteras de Sefarad, como lugar originariamente bíblico que alude a la condición de los proscritos, se extienden así, según indica Ibáñez, "de lo político a lo físico, del perseguido al enfermo, excluido ya como tras una frontera del resto de los hombres" (384). Solapando estas fronteras existenciales, el personaje de Paul Valéry, por ejemplo, define el judaísmo con "una enfermedad secreta" (700), que se revela públicamente cuando, "un día, en 194I, tuve que coserme una estrella de David amarilla en la pechera de mi abrigo" (700). De modo similar, el señor Salama compara la vergüenza que siente de niño por ser judío a la que experimenta tras sufrir un accidente de tráfico años después y quedar discapacitado. Al equiparar 
estas experiencias, Sefarad enfatiza que la exclusión no es únicamente el resultado de una causa o condición externa, sino que es también interiorizada psicológicamente por el individuo como parte de su identidad. Más aún, y a diferencia de la exclusión política en un estado totalitario, el lector percibe la enfermedad de antemano como una amenaza real que, de la noche a la mañana, podría alterar radicalmente su vida. De este modo, el paralelismo entre la exclusión política y la enfermedad permite al lector aproximarse, aunque sea de soslayo, a la situación de personajes que habitan realidades distintas pero que comparten una misma consciencia, según indica Vigdes Ahnfelt, "de los procesos de exclusión de los cuales será(n) víctima(s), a saber, el desprecio y la intolerancia de otros que generan sentidos de inferioridad y vergüenza en el enfermo" (139).

La novela supera esta aproximación empática en el capítulo "Olympia", en el que extiende el periodo de espera que experimentan personajes como Ginzburg o Münzenberg a la vida diaria de un personaje de clase media que - en lo que puede interpretarse como una proyección metaficcional del propio Muñoz Molina - vive en un estado democrático de estabilidad. Esta proyección del pasado al presente implica rechazar toda visión presentista de la historia, lo que llevaría al lector a interpretar el pasado desde una lógica contemporánea. En este relato, por el contrario - y en lo que supone un giro a la hora de relacionarnos con la historia - el pasado apela al presente para cuestionar los fundamentos y la lógica sobre los que este se sustenta. Tras este giro, la espera del narrador de "Olympia" no priva de sentido a su muerte, sino a su vida que, a pesar de la seguridad aparente de la que disfruta, carece de propósito. En cualquier caso, si en el caso de las víctimas de sistemas totalitarios o de una enfermedad terminal el horizonte de esta espera es la muerte, en el caso del narrador - y protagonista en esta ocasión - esta espera permanece indefinidamente en suspensión. Más aún, esta normalidad sitúa al protagonista de "Olympia" - y presumiblemente al lector - en la casilla de salida de la historia, desde la que se desconoce el curso que esta va a tomar y el impacto que tendrá sobre su existencia e identidad. En este sentido, la seguridad desde la que el narrador y el lector de este relato se aproximan a la historia no los distancia de las víctimas de los totalitarismos, sino que los identifica con el estado de negación que estas experimentan cuando confrontan su exclusión e incluso la posibilidad de la muerte..$^{14}$

Llegados a este punto, y en lo que supone un paso definitivo a la hora de integrar al lector en la historia de los excluidos, la novela exhorta al primero, no ya a entender o a empatizar con los personajes, sino a identificarse con sus emociones y sufrimientos. El objetivo de esta identificación hetereopática es introducir, según indica Kaja Silverman, "the 
not-me into my memory reserve" de forma que el lector pueda participar "in the desires, struggles, and sufferings of the other" (I85). Se trata en definitiva de una identificación a distancia que, como matiza Marianne Hirsch, "does not interiorize the other within the self but that goes out of one's self and out of one's own cultural norms in order to align oneself, through displacement with another" (9). El propio narrador modela esta implicación emocional que pretende estimular en el lector, como refleja el primero a través de una intrusión metaficcional que lleva a cabo en el capítulo "Dime tu nombre": "[M]e imaginaba que pertenecía al igual que ellos a un linaje de desterrados secretos, extranjeros en el lugar donde ha vivido siempre y fugitivos sedentarios que esconden su íntima rareza y su exilio congénito bajo una apariencia de perfecta normalidad" (Muñoz Molina, Sefarad 65r).

Esta identificación con la experiencia de los excluidos tiene un impacto sobre la propia identidad del narrador, quien se presenta a sí mismo, y evocando el discurso del padre del señor Salama, como un "yo" fluido y múltiple que habita la vida y el recuerdo de otros personajes: "Nunca soy más yo mismo que cuando guardo silencio y escucho; cuando dejo a un lado mi fatigosa identidad y mi propia memoria para concentrarme del todo en el acto de escuchar, de ser permanentemente habitado por las experiencias y los recuerdos de los otros" (Muñoz Molina, Sefarad 680). El narrador exige este mismo esfuerzo de identificación al lector, invitándole - desde el presente de indicativo, y superando el uso del condicional y del subjuntivo al que recurre anteriormente - a ponerse en la piel de los personajes. Dicho de otro modo, el narrador se propone una transformación del lector - de su identidad y experiencia - que supera la empatía a la que lo conduce previamente desde la hipótesis y la imaginación. En este punto, las fronteras entre pasado y presente, entre realidad y ficción, y entre el sujeto y el objeto de la experiencia acaban desdibujándose para transformar al lector en todos y cada uno de los personajes que transitan por Sefarad. El lector deja así de percibir a los personajes de la novela desde una perspectiva externa para formar parte de la comunidad de acusados que éstos conforman y, por consiguiente, del estado de excepción permanente que marca su exclusión de un tiempo, de un espacio e incluso de sí mismos. Como aclara el narrador principal de Sefarad:

Eres Jean Améry viendo el paisaje de prados y árboles por la ventanilla del coche en el que lo llevan preso al cuartel de la Gestapo, eres Eugenia Ginzburg escuchando por última vez el ruido peculiar con que se cierra la puerta de su casa, adonde nunca va a volver ... Eres quien mira la normalidad perdida desde el otro lado del cristal que te separa de ella, quien entre las rendijas de las tablas y de un vagón de deportados, 
mira las casas de la ciudad que creyó suya y a la que nunca volverá. (Muñoz Molina, Sefarad 618-19)

Como conclusión, Sefarad propone una nueva aproximación a la hora de narrar y pensar la historia, eliminando toda frontera psicológica y discursiva que permita al lector desplazar el acontecimiento histórico a un pasado pretérito que, supuestamente, nada tiene que ver con su realidad inmediata. En contraposición a un discurso histórico de corte teleológico que concibe el presente como una superación de todos los males del pasado, Sefarad aborda la historia desde aquellos acontecimientos que, a modo de interferencias, cuestionan todo ideal de progreso, como la expulsión de I492, la guerra civil española, el terror estalinista o el Holocausto. Desde una lectura literal, cada uno de estos acontecimientos está marcado por la irrupción de un estado de excepción en el que, siguiendo a Agamben, se diluye toda diferencia entre la pertenencia y la exclusión (State 23), hasta el punto de que "life and law, outside and inside, become indistinguishable" (State 9). Como consecuencia, y de forma arbitraria, los personajes de Sefarad quedan expuestos a la fuerza pura de la ley, lo que los lleva irremediablemente al exilio, a los campos de concentración e incluso a la muerte.

Por otro lado, y desde una perspectiva ejemplar, la yuxtaposición de los acontecimientos históricos que se abordan en Sefarad - así como las analogías que se establecen entre los mismos - pone de relieve la existencia de un estado de excepción que pierde, paradójicamente, su carácter de emergencia para transformarse en la hebra que hilvana el tejido de la historia. Con este propósito, Muñoz Molina recurre a una estructura formal y temática heterogénea desde la que, por un lado, destaca la singularidad de cada una de las experiencias que se narran en Sefarad, mientras que, por otro, normaliza estados de desarraigo y exclusión que superan toda particularidad histórica. Se trata, en definitiva, de la memoria de un estado de excepción constante que se inserta sutilmente en la seguridad y normalidad de un presente desde el que no se pueden anticipar los derroteros que va a seguir la historia y que subraya, como indica Benjamin en su octava tesis sobre la filosofía de la historia, que "the 'state of emergency' in which we live is not the exception but the rule" (257). En este contexto de inestabilidad e incertidumbre permanentes, Sefarad cuestiona la seguridad ontológica de un lector que se halla sujeto, al igual que los personajes que figuran en los relatos que componen esta obra, a las vicisitudes de la historia, lo que reduce toda garantía de estabilidad y permanencia a una ficción.

Colorado College 
NOTAS

I La interpretación del concepto de "Sefarad" como espacio geográfico está sujeta a múltiples interpretaciones. Javier Castaño, por ejemplo y según cita Antonio Pita, afirma que "Sefarad es un término polisémico que va evolucionando con el tiempo, adaptándose a realidades políticas y geográficas cambiantes. Según el momento, se ha empleado como equivalente hebraico de Al Andalus (e Hispania) o bien de toda la península y, más modernamente, España" (Pita). Indica este último autor, no obstante, que lo más probable "es que originalmente Sefarad no fuese España. Es decir, que la identificación entre ambas provenga de un simple error, licencia o reinterpretación en una prestigiosa traducción bíblica efectuada hace dos milenios, según coinciden la mayoría de los investigadores sobre el tema".

2 Por "lector ideal" me refiero a un lector de principios de siglo XXI que tiene una memoria lejana o transferida de los totalitarismos del siglo XX y de la guerra civil española.

3 Agamben profundiza en esta reflexión aportando como ejemplos la autorización de las comisiones militares en Estados Unidos en noviembre de 200 I como respuesta a los atentados del in de septiembre en Nueva York. Esta autorización supone una suspensión de la ley, ya que permite la detención indefinida, y sin necesidad de juicio previo, de cualquier ciudadano que sea sospechoso de participar en actividades terroristas (Agamben, State 2). Se trata de una norma extrajurídica en la que se funden la ley y la anonimia, normalizando el estado de excepción en un contexto de aparente normalidad política y social.

4 Como indica Muñoz Molina en el artículo "Travesías. Antonio Muñoz Molina, Montevideo": "En los años setenta, en la década siniestra del oscurantismo militar, la corriente de destierro se invirtió, y quienes habían acogido a los españoles fugitivos tuvieron que huir a Europa".

5 Apunta Valdivia que la expulsión de los judíos ordenada por los Reyes Católicos en 1492 "fue acogida en el resto de Europa como un signo de modernidad e incluso se conserva una felicitación de la Universidad de la Sorbona" (9I2).

6 La desaparición de los supervivientes del Holocausto implica también la disolución del imperativo kantiano que los mueve, según indica Primo Levi, a articular sus testimonios frente a quienes no pudieron volver" (45). De hecho, el superviviente italiano reconoce, tras reflexionar sobre una conversación que mantiene con jóvenes de una escuela italiana sobre su experiencia en Auschwitz, que "mi lenguaje se volvió insuficiente, que hablo una lengua diferente" (Levi 28). 
7 Muñoz Molina reflexiona sobre las características del discurso sefardí en su artículo "La nacionalidad del infortunio, publicado el 29 de noviembre de 1995 , en el que rememora su conversación con un sefardí: "Me habla con igual vehemencia del edicto de expulsión de 1492 y del exterminio de los sefardíes de Salónica en los campos nazis y en medio de una conversación sobre las cosas que ocurren ahora mismo en España se disculpa por su falta de conocimientos".

8 En una entrevista a Rosa Mora, Muñoz Molina explica la fuga musical como "una unidad de temas ... que aparecen, que desaparecen, que vuelven a aparecer, que se ven desde muchos puntos de vista" (citado en Ibáñez 387).

9 Para una explicación detallada sobre el uso de la fuga musical en Sefarad, véase la tesis doctoral El híbrido narrativo en la novela de Antonio Muñoz Molina (20I4), de María de las Nieves Ibáñez Ibáñez (368-400).

Io En Sefarad, todos los personajes desplazados tienen un acento que los delata como exiliados, como ocurre, por ejemplo, con el señor Salama (quien mantiene los dejes del ladino o judeo-español), con Amaya Ibárruri (quien tiene dificultades para distinguir entre el ruso y el español) y con sor María de Cólgota o Fanny. Se trata de una característica recurrente que permite conectar las experiencias de distintos personajes a lo largo de la novela.

II Sefarad hace referencia, e incluso reconstruye fragmentos, de las historias y biografías de un amplio elenco de personajes históricos que experimentan el Holocausto y el estalinismo, como Primo Levi, Frank Kafka, Milena Jesenska, Victor Klemperer, Heinz Neuman, Jean Améry, Eugenia Ginzburg, Nadiezhda Madelstam y Walter Benjamin.

I2 Según Agamben: "The relation of exception is a relation of ban. He who has been banned is not, in fact, simply set outside the law and made indifferent to it but rather abandoned by it, that is, exposed and threatened on the threshold in which life and law outside and inside, become indistinguishable" (Homo Sacer 28).

I3 Según Landsberg: "Modernity makes possible and necessary a new form of public cultural memory. This new form of memory, which I call prosthetic memory, emerges at the interface between a person and a historical narrative about the past at an experiential site, such as a movie theater or museum. In this moment of contact, an experience occurs through which the person sutures himself or herself into a larger history ... In the process that I am describing, the person does not simply apprehend a historical narrative, but takes on a more personal, deeply felt memory of a past event through which he or she did not live. The resulting prosthetic memory has the ability to shape this person's subjectivity and politics" (2).

I4 Como indica Primo Levi en una entrevista a Anna Bavo y Federico Cereja: “Somos lúcidos hoy en día? ¿Nos comparamos lúcidamente frente al peligro 
nuclear? El campo de batalla, si existe alguno, será Europa, y quién de nosotros, si tuviera dinero en Suiza, iría a llevárselo para exiliarse en Nueva Zelanda. En aquella época no era tan distinto. ¿Acaso nosotros no experimentamos negación?" (39).

OBRAS CITADAS

A gam B e n, gio Rgi o. Homo Sacer: Sovereign Power and Bare Life. Stanford: Stanford UP, 1998.

-. State of Exception. Chicago: U of Chicago P, 2005.

A h F E L , VIG DEs. La recuperación de la identidad en la novela Sefarad de Antonio Muñoz Molina. Tesis doctoral, U de Estocolmo, 2008.

Be NJA min, walter. "Theses on the Philosophy of History." Illuminations. Essays and Reflections. Trans. Harry Zohn. New York: Schocken Books, I988. 253-64.

B LANCHO T, MAURice. The Writing of Disaster. Trans. Ann Smock. Lincoln: U of Nebraska P, I995.

CERTEAU, M ICHEL DE. The Writing of History. Trans. Tom Conley. New York: Columbia UP, 1988.

CRUZ, M AN U E, ED. Hacia dónde va el pasado. El porvenir de la memoria en el mundo contemporáneo. Barcelona: Paidós, 2002.

DE RRIDA, J ACQ UES. Fuerza de ley. El "fundamento místico de la autoridad." Madrid: Editorial Tecnos, 2002.

f o u Ca ult, mich el. Genealogía del racismo. La Plata: Editorial Altamira, 1996.

—. "History of the Systems of Thought." Language, Counter-memory, Practice. Ed. Donald F. Bouchard. Ithaca: Cornell UP, 1980. 199-205.

—. Nietzsche, la genealogía, la historia. Valencia: Pre-textos, 1997.

G A D A M E R, H A N S-GE OR G. El problema de la conciencia histórica. Trans. Agustín Domingo Moratalla. Madrid: Tecnos, 2000.

GADAMER, NICOLA. "The Afterlife of Traumatic Memories: The Workings and Uses of Empathy in Antonio Muñoz Molina's Sefarad." Bulletin of Spanish Studies 88.6 (2OII): 839-62.

GÓ MEZ L ĹPEZ-QUiñones, ANTONio. "El Holocausto según Antonio Muñoz Molina: Ética y escritura en Sefarad.” Ojáncano: Revista de Literatura Española 26 (2004): 59-75.

G O Y is l l, JuAn. El sitio de los sitios. Madrid: Alfaguara, I995.

HERZBERGER, DAVID. "La disciplina de escritor: el columnismo literario de Antonio Muñoz Molina." El columnismo de escritores españoles (1975-2005). Eds. Alexis Grohman y Maarten Steenmeijer. Madrid: Verbum, 2006. 45-58.

H IRSCH, MAR IA N E. The Generation of Postmemory: Writing and Visual Culture After the Holocaust. New York: Columbia UP, 2012. 
I BÁ Ñ EZ I BÁÑEZ, M A Rí A DE LAS NIEves. El “híbrido narrativo" en la novela de Antonio Muñoz Molina. Tesis doctoral, U de la Rioja, 20I4. Web.

LAN DS BERG, A Lis on. Prosthetic Memory: The Transformation of American Remembrance in the Age of Mass Culture. New York: Columbia UP, 2004 LEVI, PRIm o. Deber de memoria. Trans. Octavio Kulesz. Buenos Aires: Libros del Zorzal, 2006.

López navarro, maría jesús. "Estudio crítico de Sefarad, novela de novelas." Annali Online di Ferrara 2 (2006): 75-III.

martín lareque, eduardo. "Sefarad. Una novela de novelas, de Antonio Muñoz Molina." Lengua Secundaria. S. pag. Web.

MUÑ OZ MOLINA, AN Tonio. "La nacionalidad del infortunio." El País, 29 noviembre I995. S. pag. Web.

—. "Mis compatriotas." El País, 6 noviembre i996. S. pag. Web.

-. Sefarad. $2^{\text {a }}$ ed. Ed. Pablo Valdivia. Madrid: Cátedra, 2013.

—. "Travesías. Antonio Muñoz Molina. Montevideo." El País, 23 octubre i996. S. pag. Web.

PÉREZ Simón, ALBERTo. "La ficción difícil: la escritura memorialista de Antonio Muñoz Molina." Romance Notes 54.2 (2014): 253-6r.

Pit A, A T T N Io. "El traductor que convirtió Sefarad en España." El País, i4 abril 2017. S. pag. Web.

SERnA, JUS T o. "Pasados posibles. Memoria, ficción y vida en Antonio Muñoz Molina." Revista de pensamiento contemporáneo 8 (2002): S. pag.

silverman, kaja. The Threshold of the Visible World. New York: Routledge, 1996. T O D ROV , T ZVET A . Los abusos de la memoria. Trans. Miguel Salazar. Barcelona: Editorial Paidós Ibérica, 2000.

T U N ON DE LARA, MAN U E. Metodología de la historia social de España. I ed. Madrid: Siglo XXI de España Editores, 1973.

ŽIŽ E K, SL A V o J. The Metastases of Enjoyment. Six Essays on Woman and Causality. London: Verso, I994. 